\title{
Promoting research and training in Europe
}

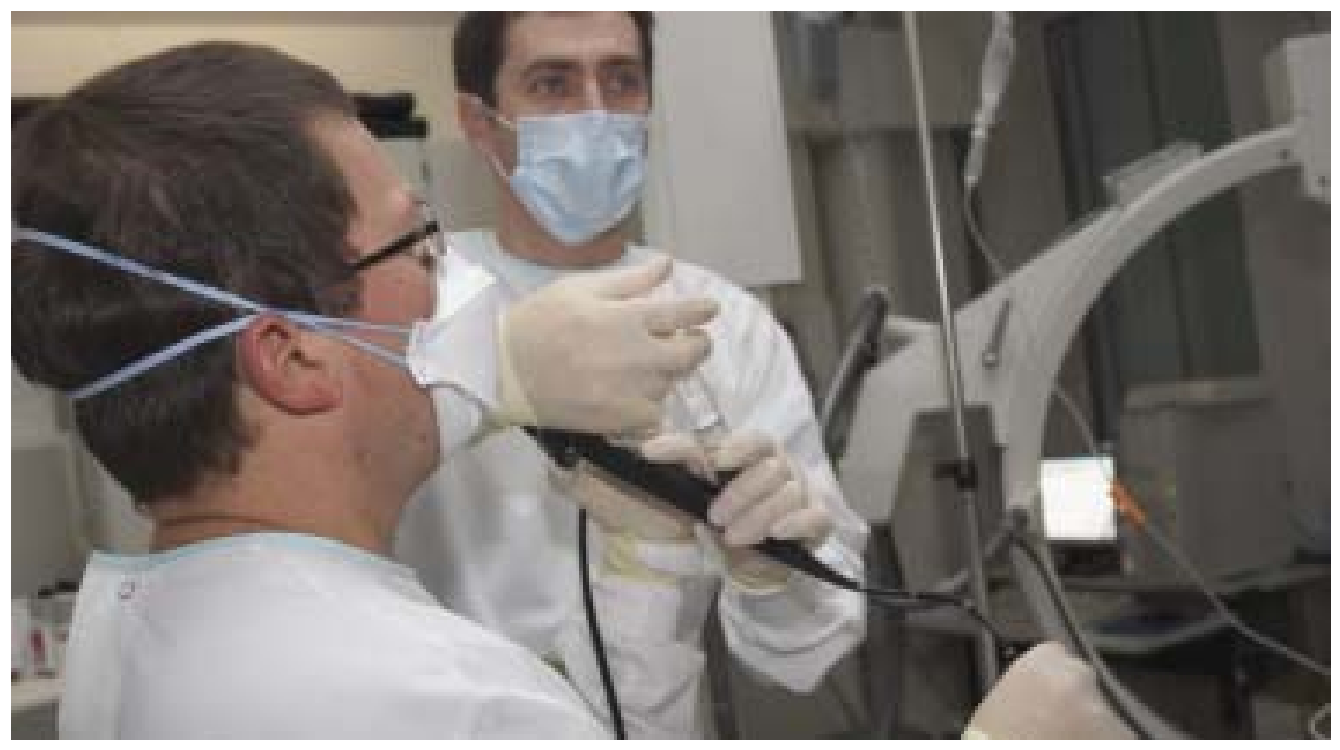

\section{ERS Fellowships}

Since its foundation in 1991, the European Respiratory Society (ERS) has been committed to ensuring high standards of respiratory medicine in Europe and providing a platform from which the next generation of respiratory specialists can grow. As a result, the ERS believes that sustained learning is the source for future developments and, therefore, continues to promote research and training wherever possible.

\section{What is an ERS Fellowship?}

ERS Fellowship schemes provide investigators and clinicians with the financial support to undertake respiratory research or a training project in a different European centre, enabling them to acquire expertise that cannot be acquired in their own countries. Applications for funding are selected on the following criteria: the relevance of the research question or training project; the likelihood of obtaining an answer or adequate expertise; the quality of the host laboratory and supervisor; and the quality of the applicant.
Decisions on awarding the Fellowships are made by the ERS Scientific Committee (research fellowships) and by the ERS School (training fellowships). Special consideration is given to young researchers and to applications from lowincome countries.

\section{Who can apply?}

Young investigators and clinicians with the appropriate professional qualifications and experience to carry out their proposed projects can apply. Candidates must be aged under 40 years at the time of application deadline and be proficient in a language enabling effective communication at the host institution.

\section{How to apply}

Full details of the different types of Fellowship, including general conditions and guidelines, can be accessed on the ERS website, www.ersnet.org/ fellowships. Applications intended for the development and implementation of specific medical techniques in developing, Central and Eastern European countries are particularly encouraged.

\section{Fellowships deadlines}

I Long-term Fellowships: January 15, 2006

I Short-term Fellowships: April 1,

October 1,

December 1, 2006

\section{New for 2006}

I ERS Fellowships are renewable

I Applicants do not need to hold a position

I ERS Fellowships can extend existing grants 


\section{Annual awards}

\section{The ERS Romain Pauwels Research Fund 2005}

Supported by GlaxoSmithKline

Prize winner: Bart Lambrecht (Rotterdam, the Netherlands)

\section{ERS Awards}

Applications for the 2006 ERS COPD Research Awards and Romain Pauwels Research Fund have to be submitted online by February 23, 2006. For more information go to www.ersnet.org/pauwels or www.ersnet.org/copd-award

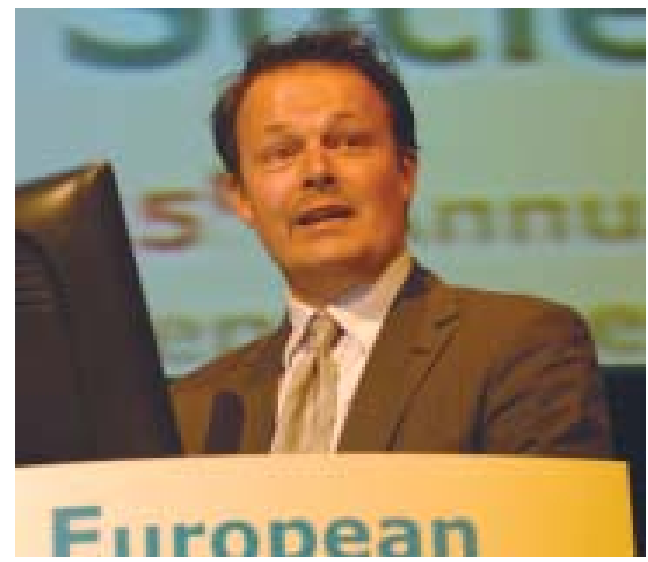

This award honours the memory of Professor Romain Pauwels and his efforts in fighting asthma and COPD. It aims to encourage a new generation of clinically orientated lung disease scientists in their quest to understand and treat airway diseases.

The first of these awards was presented to Bart Lambrecht during the ERS Congress in Copenhagen. Bart was born and educated to degree and PhD level at the University of Ghent. His $\mathrm{PhD}$ project dealt with the role of dendritic cells in asthma, and was performed under the supervision of Professor Romain Pauwels.

Subsequently, Bart moved to the Netherlands where he trained in Pulmonary Medicine under the supervision of Professor Henk Hoogsteden. Currently, Bart is heading a group of 20 scientists within the Pulmonary Research Programme of Erasmus University in Rotterdam. In 2005, he was appointed Professor of Pulmonary Medicine, with a special interest in the immunopathology of the lung.

The interest of his research group is on the role of antigen-presenting dendritic cells in the initiation of the pulmonary immune response that ultimately leads to sensitisation to aeroallergens. One of the group's major discoveries was that dendritic cells are not only crucial in inducing sensitisation to inhaled antigen, but they are also essential for T-cell activation during established allergic inflammation, and, therefore, constitute ideal targets for novel therapeutic intervention. Moreover, a major finding was that certain subsets of dendritic cells might actually protect against asthma development.

\section{The ERS COPD Research Awards 2005}

Supported by Boehringer Ingelheim

\author{
1st prize: Borja Cosio (Palma de Mallorca, \\ Spain)
}

Borja Cosio graduated from Universidad Complutense Medical School and underwent specialist clinical respiratory training at the Hospital Universitario 12 de Octubre, Madrid, Spain. In 2000, he moved to London (UK) to work in a research laboratory under the supervision of Professors Peter Barnes and lan Adcock.

In September 2003, Borja moved to Palma de Mallorca, where he is currently working with $\mathrm{Dr}$ Alvar Agusti, developing new lines of research aimed at understanding the pathobiology of COPD exacerbations. The main contribution of his work has been to explore the role of histone acetylation/deacetylation disbalance in the inflammatory processes that characterise COPD, and comparing it with asthma. This was the beginning of a larger study conducted by $\mathrm{Dr}$ Kazuhiro Ito, of which Borja is a co-investigator, which explored the relationship between decreased histone deacetylase activity and COPD severity.

Borja is currently exploring the role of NF- $\mathrm{KB}$ activation and histone acetylation/deacetylation disbalance during COPD exacerbations.

\section{2nd prize: Thomas Wilkinson (London, UK)}

Tom Wilkinson graduated from Cambridge University and completed his clinical studies at $\mathrm{St}$ Bartholomew's and the Royal London Hospital Medical School. His initial research training was with Professor Wedzicha and the East London COPD research group. He has recently moved with this group to University College London, and is currently working as a clinical lecturer based at the Royal Free Hospital.

Tom's interests are the role of acute and chronic airway infection in COPD, particularly with respect to disease progression and the pathogenesis of acute exacerbations. Airway infection has long been identified as a factor that may play a role in the pathogenesis of COPD. Tom and colleagues have been the first to demonstrate a direct relationship between airway bacterial colonisation and FEV1 decline and, hence, suggest a potential target for intervention, which may alter the natural history of this disease. 